\title{
Prenatal Sonographic Diagnosis of Musculoskeletal Anomalies in South Western Nigeria: A Hospital-based Study
}

Janet A Akinmoladun

\begin{abstract}
Introduction: Musculoskeletal anomalies are the second most common anomalies after anomalies of the central nervous system. The presence of these anomalies in children can cause emotional upset and social stigma to the affected parents. Early detection of these anomalies is important in the management of the condition and may help to reduce perinatal morbidity and mortality associated with them. The objective of this study is to describe the musculoskeletal anomalies diagnosed during prenatal ultrasound screening for anomalies in our center, the associated anomalies and outcomes.

Materials and methods: This is a retrospective evaluation of all cases of musculoskeletal anomalies detected during prenatal ultrasound screening for fetal anomalies at the University College Hospital, Ibadan, Nigeria between 2012 and 2018.

Results: Two thousand six hundred and thirty-four $(2,634)$ fetuses were screened prenatally with ultrasound for anomalies over a 6-year period. A total of $14(0.4 \%)$ of the fetuses had musculoskeletal anomalies. Four (28.6\%) of the anomalies were isolated while the remaining had associated anomalies involving other systems. Seven (50.0\%) of the pregnancies with these anomalies were terminated before term because of the severity and/or associated anomalies. Six (42.9\%) of the fetuses were delivered at term of which three had early neonatal death.

Conclusion: Prenatal screening for anomalies affecting the musculoskeletal system is essential in the primary prevention of disability and reducing perinatal mortality and morbidity.
\end{abstract}

Keywords: Congenital anomalies, Fetus, Musculoskeletal, Prenatal diagnosis, Ultrasound.

Donald School Journal of Ultrasound in Obstetrics and Gynecology (2021): 10.5005/jp-journals-10009-1824

\section{INTRODUCTION}

The introduction of prenatal screening for fetal anomalies to midtrimester ultrasonography has significantly improved antenatal care by reducing the perinatal morbidity and mortality associated with major congenital anomalies (CAs). This screening involves a systematic and detailed thorough evaluation of fetal anatomy to rule out anomalies. This is in addition to the routine determination of the position of the placenta, assessment of the amniotic fluid, and measurement of fetal growth. ${ }^{1-3}$

A CA is an abnormality of structure, functions, or body metabolism that is present at birth (even if not diagnosed until later in life) and results in physical or mental disability or death. ${ }^{2}$ According to World Health Organization (WHO), ${ }^{2} \mathrm{CAs}$ result in an estimated 3.2 million birth defect-related disabilities every year. CAs, regardless of their cause, can affect any organ or system of the body but some systems are more commonly affected than the others. ${ }^{4}$

Musculoskeletal (MSK) anomalies are disorders affecting one or a combination of bone and muscle development in the skull, trunk, and limbs. They have been reported by the WHO as the second most common birth defect after central nervous system anomalies with a prevalence of $51.12 / 1,000$ population. ${ }^{5}$ However, some other studies reported anomalies of MSK system as the most common anomalies. ${ }^{6,7}$ These anomalies have been linked to various teratogens applied during intrauterine life, producing permanent postnatal changes in morphology or function. Such teratogens can be drugs such as thalidomide, infections such as rubella, radiations, chromosomal disorders, and nutritional deficiencies. ${ }^{8-11}$ MSK defects have also been associated with various maternal factors such as maternal age, parity, and antenatal illnesses. .,11,12 $^{2}$
Department of Radiology, University College Hospital, Ibadan, Oyo State, Nigeria

Corresponding Author: Janet A Akinmoladun, Department of Radiology, University College Hospital, Ibadan, Oyo State, Nigeria, Phone: +234-8024747372 e-mail: jaakinmoladun@yahoo.com

How to cite this article: Akinmoladun JA. Prenatal Sonographic Diagnosis of Musculoskeletal Anomalies in South Western Nigeria: A Hospital-based Study. Donald School J Ultrasound Obstet Gynecol 2021;15(4):401-406.

Source of support: $\mathrm{Nil}$

Conflict of interest: None

One of the major steps in reducing the incidence of MSK anomalies and proper management is early detection of the anomalies. $^{3,13-15}$ Studies have shown that up to $96 \%$ of all fetal anomalies are detectable by ultrasonography before the 17th week of gestation while most skeletal defects will be detected during a detailed ultrasonographic scanning between 18 and 22 weeks of pregnancy. ${ }^{3,13,15}$ The ability to identify such conditions during the first or second trimester of pregnancy can facilitate alternative approaches for managing affected pregnancies, such as delivery and care of the infant at a tertiary center, undertaking therapeutic interventions during gestation (e.g., fetal surgery), or electively termination of the pregnancy. $9,12,15,16$ When defects are severe or life-threatening, selective termination of the pregnancy may frequently be chosen and this will partially reduce the incidence of congenital malformations among newborns. ${ }^{15,16}$ The objectives of this study are to describe the MSK anomalies diagnosed during

(0The Author(s). 2021 Open Access This article is distributed under the terms of the Creative Commons Attribution 4.0 International License (https://creativecommons. org/licenses/by-nc/4.0/), which permits unrestricted use, distribution, and non-commercial reproduction in any medium, provided you give appropriate credit to the original author(s) and the source, provide a link to the Creative Commons license, and indicate if changes were made. The Creative Commons Public Domain Dedication waiver (http://creativecommons.org/publicdomain/zero/1.0/) applies to the data made available in this article, unless otherwise stated. 
prenatal ultrasound screening for anomalies in our center, their associated anomalies, and their outcomes.

\section{Materials and Methods}

This was a retrospective evaluation of all cases of MSK anomalies seen during prenatal ultrasound screening for fetal anomalies at the University College Hospital (UCH), Ibadan, Nigeria between 2012 and 2018. UCH is a federal tertiary teaching hospital located in South West Nigeria and it is also a referral center for state hospitals and community centers. The hospital runs many consultative clinics, which include an antenatal clinic. A dedicated ultrasound unit is sited at the antenatal clinic for easy access by patients attending the clinic

All UCH antenatal clinic patients with gestational ages (GAs) between 18 and 24 weeks who presented at the ultrasound suite for detailed midtrimester screening for CAs during the study period were included in the study. Pregnant women who had fetuses with suspected anomalies from ultrasound scans done at referral centers referred to $\mathrm{UCH}$ for second opinions were also included in the study.

All the patients were scanned by radiologists with expertise in obstetric ultrasound using the Sonix touch and Voluson P6 General Electric (GE) ultrasound machines. The guideline for performing midtrimester ultrasound by the International Society for Ultrasound in Obstetrics and Gynecology (ISUOG) ${ }^{3}$ was used in the prenatal assessment of the fetuses for anomalies. Those fetuses who had anomalies involving any one or a combination of bone and muscle development in the skull, trunk, and limbs were included in the study. The presence of associated anomalies in other body systems was also documented.

Data analysis was done by simple proportion and percentages using the Statistical Package for Social Sciences (SPSS) version 20.0 software.

\section{Results}

Over a 6-year period, 2,634 fetuses of mothers who presented for routine fetal anomaly ultrasound scans were screened. Fourteen of the fetuses had MSK anomalies giving a prevalence of $4 / 1,000$ pregnancies. Seven (50\%) of the anomalies were detected during the midtrimester prenatal screening for anomalies between 18 and 22 weeks' GA, 3 (21.4\%) between 22 and 28 weeks' GA, while $4(28.6 \%)$ were detected after 28 weeks' GA.

Four (28.6\%) of these anomalies involved only MSK system while the remaining had anomalies involving other systems. Those with solely MSK anomalies include a case each of osteogenesis imperfecta, achondroplasia, unilateral club foot, and bilateral absence of both forearms (Fig. 1). Those with associated anomalies involving other systems include a case each of bilateral clubfeet, unilateral absence of the entire upper limb, polydactyly of the fingers, two cases of thanatophoric dysplasia, and three cases of spina bifida (Table 1).

The most common of the associated anomaly was hydrocephalus (Figs 1 and 2) which accounted for $54.5 \%$, followed by hypoplastic cerebellum (18.2\%). Increased amniotic fluid was detected in seven $(50 \%)$ of the cases (Table 1 ).

Seven $(50.0 \%)$ of the pregnancies with these anomalies were terminated before term because of the severity and/or associated anomalies (Figs 2 and 3). Six (42.9\%) were delivered at term out of which three had early neonatal death(Figs 1 and 4) while one (9.1\%) was lost to follow-up (Table 1).

Twelve $(85.7 \%)$ of the MSK anomalies were confirmed postdelivery or post-termination of pregnancy. Nine (64.3\%) were confirmed by clinical evaluation, while three $(21.9 \%)$ had both clinical and radiological evaluation (Table 1, Figs 1, 2, and 4).

\section{Discussion}

The prevalence of musculoskeletal anomalies in this study is 4 in 1,000 pregnancies, which is similar to the incidence recorded by Agrawal et al. ${ }^{8}$ in India who recorded an incidence of 4 in 1,000 births. The incidence is however higher than what was reported by Prashar et al. ${ }^{17}$ and Shylaja et al., ${ }^{12}$ also in India, who both reported 3.2 in 1,000 as well as Nelson et al. ${ }^{18}$ who reported an incidence of 2 in 10,000 . Greater incidences were reported in studies by Tayebi et al., ${ }^{19}$ Gupta et al., ${ }^{20}$ and Oyinbo et al. ${ }^{21}$ who reported 14.2/1,000, $13 / 1,000$, and $31 / 1,000$, respectively. The variability in the incidence of MSK anomalies reported may be due to many reasons, which include-different genetic makeup and environmental factors, experience of the persons making the diagnosis; whether the
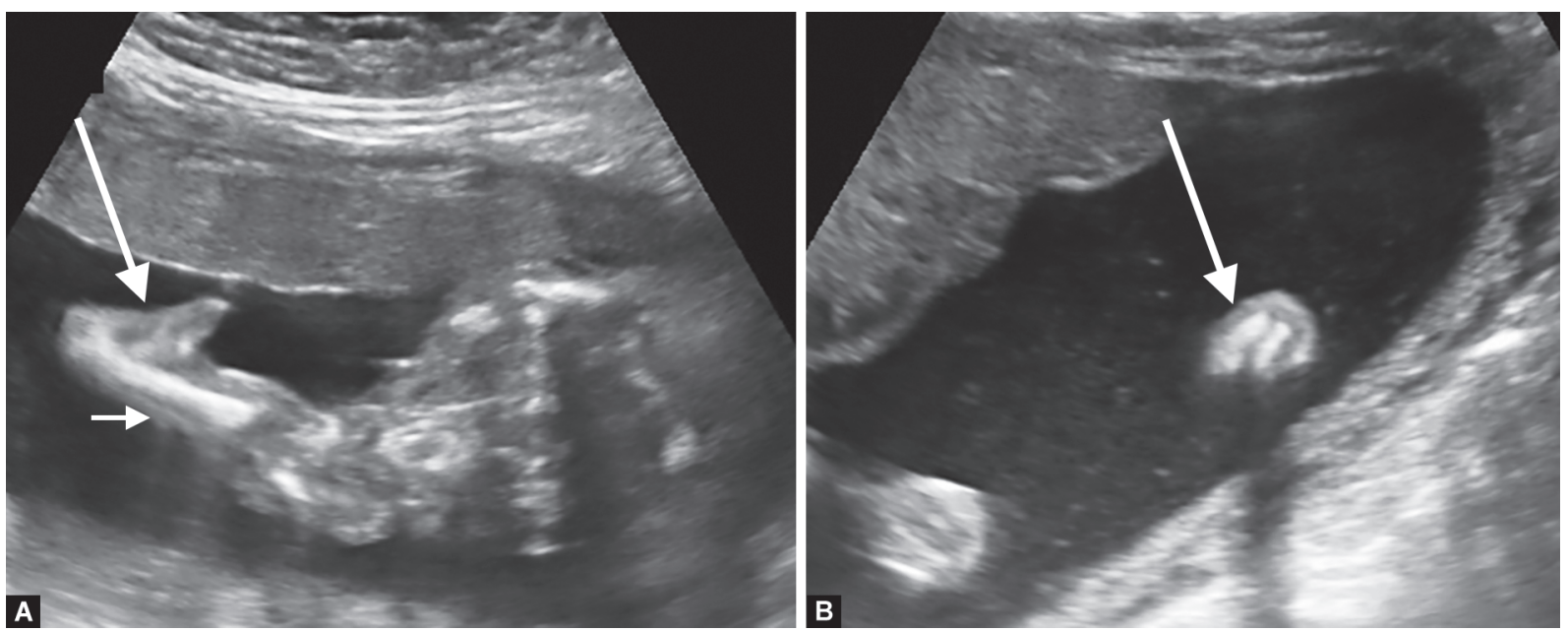

Figs 1A and B: A fetus at 20 weeks' gestational age (GA) with bilateral hypoplastic ulna and radius. (A) Ultrasound image of one of the upper limbs showing a normal sized humerus (short arrow) with shortened forearm (long arrow) and absent hand; (B) Ultrasound image of the forearm in longitudinal plane showing hypoplastic ulna and radius (long arrow). Pregnancy was terminated and anomaly confirmed by clinical evaluation 
Table 1: The frequencies of the various anomalies, outcome, and presence of associated anomalies

\begin{tabular}{|c|c|c|c|c|c|c|}
\hline Type of anomaly & Frequency (\%) & $\begin{array}{c}\text { GAat } \\
\text { diagnosis(wks) }\end{array}$ & Outcome & $\begin{array}{l}\text { Diagnosis con- } \\
\quad \text { firmed }\end{array}$ & $\begin{array}{l}\text { Associated } \\
\text { anomalies }\end{array}$ & Amniotic fluid \\
\hline Spina bifida & $3(21.42)$ & $\begin{array}{l}20 \\
30 \\
35\end{array}$ & $\begin{array}{l}\text { TOP } \\
\text { Live delivery } \\
\text { Live delivery }\end{array}$ & $\begin{array}{l}\text { Yes (cli) } \\
\text { Yes(cli/rad) } \\
\text { Yes (cli/rad) }\end{array}$ & $\begin{array}{l}\text { Yes } \\
\text { Yes } \\
\text { Yes }\end{array}$ & $\begin{array}{l}\text { Increased } \\
\text { Normal } \\
\text { Increased }\end{array}$ \\
\hline Abnormal skull shape & $2(14.29)$ & $\begin{array}{l}22 \\
26\end{array}$ & $\begin{array}{l}\text { TOP } \\
\text { Live delivery with } \\
\text { ENND }\end{array}$ & $\begin{array}{l}\text { No } \\
\text { Yes (cli) }\end{array}$ & $\begin{array}{l}\text { Yes } \\
\text { Yes }\end{array}$ & $\begin{array}{l}\text { Normal } \\
\text { Normal }\end{array}$ \\
\hline Thanatophoric dysplasia & $2(14.29)$ & $\begin{array}{l}20 \\
34\end{array}$ & $\begin{array}{l}\text { TOP } \\
\text { Live delivery with } \\
\text { ENND }\end{array}$ & $\begin{array}{l}\text { Yes (cli) } \\
\text { Yes (cli) }\end{array}$ & $\begin{array}{l}\text { Yes } \\
\text { Yes }\end{array}$ & $\begin{array}{l}\text { Increased } \\
\text { Increased }\end{array}$ \\
\hline Osteogenesis imperfecta & $1(7.14)$ & 22 & TOP & Yes (cli) & No & Normal \\
\hline Achondroplasia & $1(7.14)$ & 32 & Live delivery & Yes (cli/rad) & No & Increased \\
\hline Polydactyly & $1(7.14)$ & 25 & $\begin{array}{l}\text { Live delivery with } \\
\text { ENND }\end{array}$ & Yes (cli) & Yes & Increased \\
\hline $\begin{array}{l}\text { Bilateral hypoplastic ulna/ } \\
\text { radius (absent hands) }\end{array}$ & $1(7.14)$ & 20 & TOP & Yes (cli) & No & Normal \\
\hline $\begin{array}{l}\text { Unilaterally absent upper } \\
\text { limb }\end{array}$ & $1(7.14)$ & 21 & TOP & Yes (cli) & Yes & Normal \\
\hline Unilateral clubfoot & $1(7.14)$ & 20 & Lost to follow-up & No & No & Normal \\
\hline Bilateral clubfeet & $1(7.14)$ & 22 & TOP & Yes (cli) & Yes & Increased \\
\hline Total & $14(100.00)$ & & & 100 & & \\
\hline
\end{tabular}

ENND, Early neonatal death; cli, clinical; rad, radiological; wks, weeks; TOP, termination of pregnancy
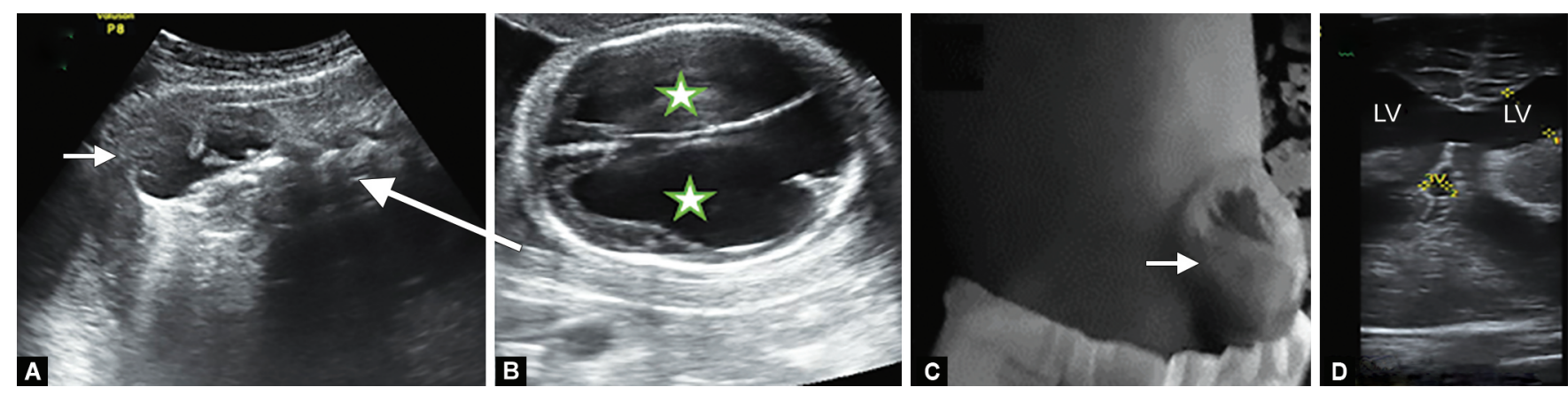

Figs 2A to D: A 35-week-old fetus with meningomyelocele and ventriculomegaly. (A) Prenatal ultrasound image of a fetus showing a cystic mass (short arrow) over the lower back (long arrow) at the level of the lumbosacral spine junction consistent with spinal bifida with meningomyelocele; (B) Ultrasound of the fetal skull in transverse plane showing associated severe dilatation of both lateral ventricles (stars); (C) Photograph of the baby after delivery with the cystic mass (arrow) seen over the lower back; (D) A trans-fontanel ultrasound of the baby confirming the dilated lateral ventricles (LV) and third ventricle (3V)

data includes only live born or stillborn babies and the spectrum of investigations carried out in confirmation of the diagnosis., ${ }^{9,12}$

Congenital talipes equinovarus (CTEV) or clubfoot has been reported in many studies as the most common anomaly of the MSK system. ${ }^{8,9,12,17,22,23}$ This may be due to the fact most of these studies considered only anomalies of the limbs and most of them were done in newborns in which this anomaly is usually very obvious. Some other studies are however at variance with this, for example, Nelson et al. ${ }^{18}$ reported osteogenesis imperfecta as the most common MSK anomaly, while Simpkiss et al. ${ }^{24}$ and Bakare et al. ${ }^{23}$ reported polydactyly as the most common anomalies. Spinal bifida with meningomyelocele was the most common anomaly in this study, while clubfoot was only reported in two of the fetuses, one bilateral and one unilateral.

The presence of concomitant abnormalities in other organ systems has been associated with increased morbidity and mortality in MSK anomalies. ${ }^{16}$ Therefore, it is very important to routinely assess other parts of the fetus once the diagnosis is made to rule out other abnormalities. Concomitant anomalies of the cardiovascular and genitourinary systems were reported in a study by Vasluian et al. ${ }^{25}$ Mammen et al. ${ }^{26}$ in their study showed that associated anomalies were more common with fetuses with bilateral clubfeet and these include hydrocephalus, neural tube defects, cleft lip/palate and heart defects, and/or chromosomal abnormalities. Associated anomalies were reported in 10 (71.4\%) of our cases with hydrocephalus being the most common, detected in six (54.5\%) of the fetuses.

Abnormalities of amniotic fluid have also been indicated in some MSK anomalies even though it is usually reported more in neural tube defects and gastrointestinal anomalies. ${ }^{27,28}$ Taksande et al. ${ }^{27}$ and Shawky et al. ${ }^{28}$ in their studies found increased amniotic fluid in some of the fetuses with MSK anomalies. Prashar et al. ${ }^{17}$ on 

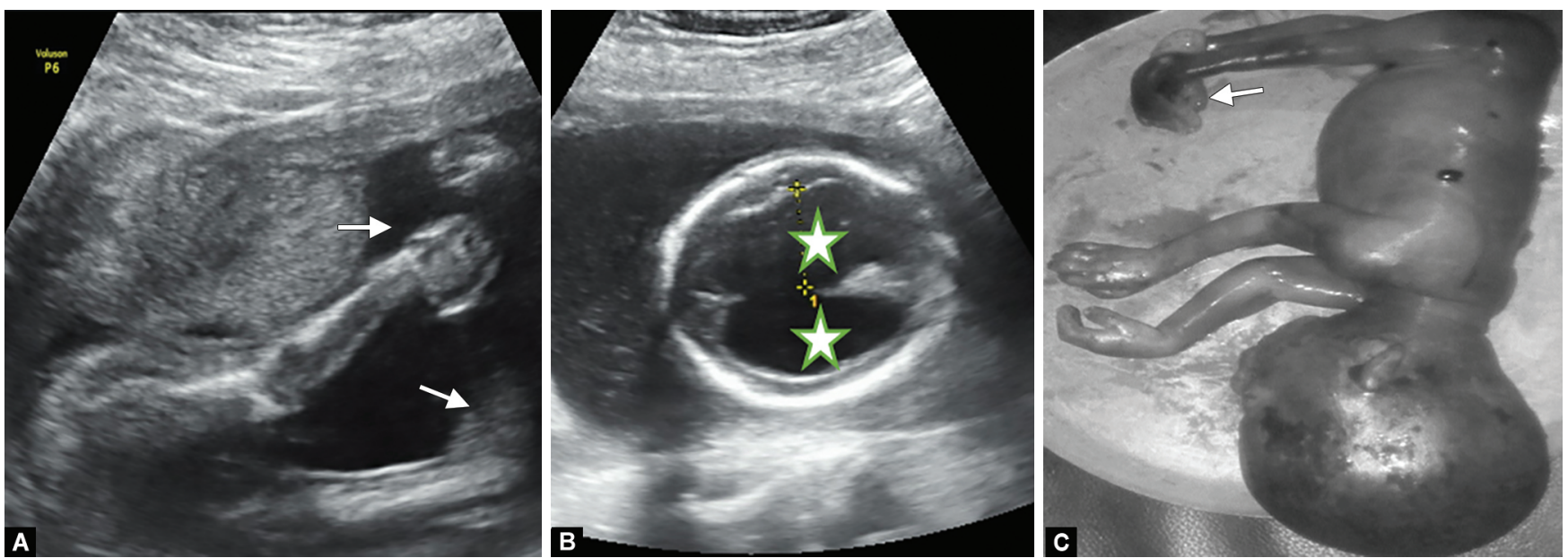

Figs $3 \mathrm{~A}$ to C: Bilateral clubbed feet associated with bilateral ventriculomegaly in a 22-week old fetus. (A) Prenatal ultrasound image of the fetus showing bilateral clubbed feet (arrows); (B) ultrasound of the fetal brain showing severe dilatation of both lateral ventricles (stars); (C) Photograph of the baby after pregnancy termination confirming the clubbed feet (arrow)
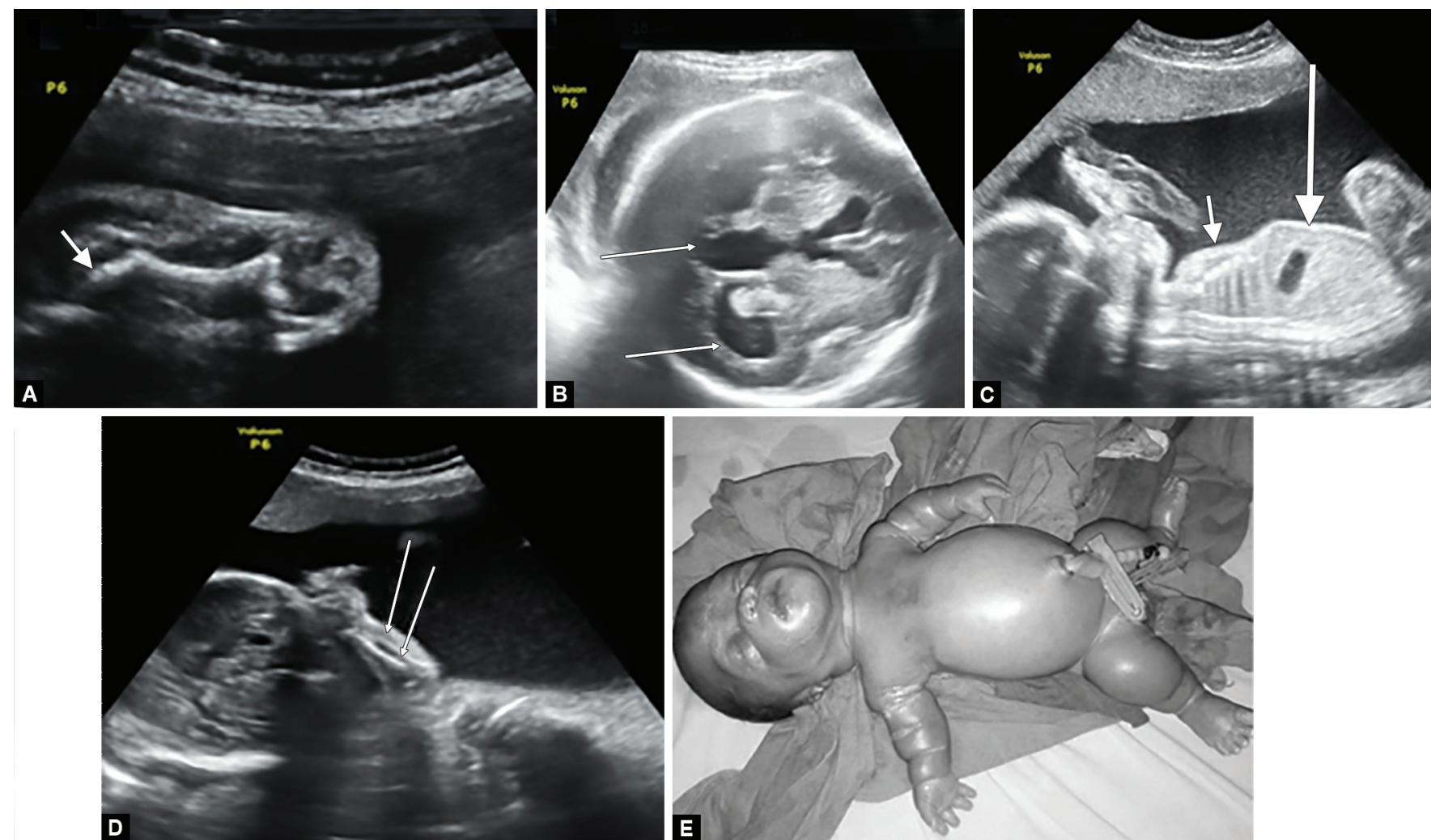

Figs 4A to E: A 24-week-old fetus with thanatophoric dysplasia associated with ventriculomegaly. (A) A longitudinal ultrasound scan of one of the fetal thigh showing a short, thick, slightly bowed femur (short arrow) with surrounding thickened soft tissue; (B) Ultrasound image of the fetal skull showing macrocephaly with dilatation of the posterior horns of both lateral ventricle (slim arrows); (C) Longitudinal ultrasound image of the fetus showing a narrow thoracic cavity (short arrow) with protuberant abdomen (long arrow); (D) Ultrasound image of the fetal forearm showing short bones (slim arrows); (E) Photograph of the baby after delivery showing a narrow thorax, protuberant abdomen, short limbs, and macrocephaly

the contrary reported oligohydramnios in 4 of the 49 fetuses with MSK anomalies, while polyhydramnios was reported in only one case. In this study, increased amniotic fluid was found in seven $(50 \%)$ of the fetuses, which shows that there should be a high level of suspicion of MSK anomalies in mothers with polyhydramnios for CAs especially when the commonly associated anomalies are absent.

The significance of diagnosis of congenital malformations of the MSK system lies not only in their contribution to mortality but also in causing disability and handicaps to the children when 
born. ${ }^{16,17}$ Their presence can also cause emotional upset and social stigma to the affected parents especially in low-/middle-income countries where the social support system is very poor. ${ }^{29}$

In most cases, primary prevention is not possible, therefore prenatal diagnosis by ultrasound scan affords the early diagnosis of the anomalies, some of which can be detected as early as 14 weeks' GA. ${ }^{15}$ The earliest GA at diagnosis in this study was 20 weeks and this may be due to the fact that prenatal screening for anomalies is done between 18 and 22 weeks' GA in our center.

In cases where a major structural defect is identified, the mother can be counseled on the possibility of either continuing with the pregnancy or terminate it. ${ }^{16,18}$ If the pregnancy is continued, the risk of stillbirth or early neonatal death should be explained to the parents. In our study, seven (50\%) of the mothers opted for termination of pregnancy, and of those who continued with the pregnancies, half of them had early neonatal death. The reason for the high rate of termination in our study could be because of the cost of managing a malformed baby, the stigma attached to families with such babies in our environment and lack of social support. On the contrary, in a study by Nelson et $\mathrm{al}^{18}{ }^{18}$ in the USA, only $16 \%$ of the parents with fetuses with MSK anomalies opted to terminate the pregnancies while more than $70 \%$ were continued to term with $4 \%$ stillbirths. The low rate of termination of pregnancy in the USA may be attributed to the good social support and well-organized National Health Scheme in the country.

When a fetus is suspected to have a MSK anomaly, it is very important to have the diagnosis confirmed postdelivery or postmortem. This confirmation could be made by clinical and/or radiological evaluation. It is also essential to have the photographs taken and in case of abortion or early neonatal death, autopsies should be offered and encouraged for accurate diagnosis. ${ }^{16}$ In this study, $12(85.7 \%)$ out of the 14 cases were confirmed, $10(83.3 \%)$ of them by only clinical evaluation while $2(16.7 \%)$ had in addition radiological assessments. Some of the photographs were also taken, but no postmortem assessment was done for any.

A major concern of families who have or have lost a child with CA is the possibility of recurrence of the anomaly in future pregnancies. Therefore, there is need for genetic counseling on the risk of recurrence of the anomaly, which provides guidance and support for those families. ${ }^{13,16}$ This is a major challenge in the developing world and also in this present study where molecular testing to confirm the diagnosis which aids in the counseling is not usually done because it is very expensive and not readily available.

\section{Conclusion}

Congenital anomalies are major contributors to perinatal morbidity and mortality. They also cause emotional upset and social stigma to parents with affected children. Prenatal screening for these anomalies, especially those affecting the MSK system, is very essential in the primary prevention of disability and reducing perinatal mortality and morbidity.

\section{References}

1. National Birth Defects Prevention Network. (2004). National Center on Birth Defects and Developmental Disabilities Guidelines for Conducting Birth Defects Surveillance. [online] Available from: http://www.nbdpn.org/birth_defects_surveillance_gui.php. [Last accessed October, 2021].

2. Akinmoladun JA, Ogbole GI, Lawal TA, et al. Routine prenatal ultrasound anomaly screening program in a Nigerian university hospital: Redefining obstetrics practice in a developing African country. Niger Med J 2015;56:263-269 DOI: 10.4103/0300-1652.169705

3. Salomon IJ, Alfirevic Z, Berghella V, et al. Practice guidelines for performance of the routine mid-trimester fetal ultrasound scan. Ultrasound Obstet Gynecol 2011;37(1):116-126. DOI: 10.1002/uog.8831

4. World Health Organization. (2013). Birth Defects in South-east Asia. A Public Health Challenge.[online] Available from https://apps.who. int/iris/handle/10665/204821. [Last accessed October, 2021].

5. WHO. Congenital anomalies, fact sheet. Geneva: WHO; 2015.

6. Swain S, Agrawal A, Bhatia BD. Congenital malformations at birth. Indian Pediatr 1994;31:1187-1191. PMID: 7875778

7. Mishra PC, Baveja R. Congenital malformations in the newborn: A prospective study. Indian Pediatr 1989;26:32-35. PMID: 2788132

8. Agrawal D, Mohanty BB, Sarangi R, et al. Study of incidence and prevalence of musculoskeletal anomalies in a tertiary care hospital of eastern India. J Clin Diagn Res 2014;8(5)AC04-AC06. DOI: $10.7860 / J C D R / 2014 / 7882.4380$

9. Kumari OM, Singh V. Prevalence and pattern of congenital musculoskeletal anomalies: a single centre study. J Clin Diag Res 2018;12(1)QC16-QC19. DOI: 10.7860/JCDR/2018/31651.11111

10. Froster UG, Baird PA. Maternal factors, medications, and drug exposure in congenital limb reduction defects. Environ Health Perspect 1993;101(Suppl3):269-274. DOI: 10.1289/ehp.93101s3269

11. Holmes LB. Teratogen-induced limb defects. Am J Med Genet 2002;112(3):297-303. DOI:10.1002/ajmg.10781

12. Shylaja DK, Menasinkai SB, Ramesh BR. Study of incidence of congenital musculoskeletal malformations and its relation to maternal age, parity and birth weight of the newborn. Indian J Clin Anat Physiol 2017;4(4):546-551. DOI: 10.18231/2394-2126.2017.0135

13. Keret $D$, Bronshtein $M$, Wientroub S. Prenatal diagnosis of musculoskeletal anomalies. Clin Orthop Relat Res 2005;434:8-15 DOI:10.1097/00003086-200505000-00003

14. Noel A, Brown RN. Advances in evaluating the fetal skeleton. Int J Womens Health 2014;6:489-500 DOI: 10.2147/IJWH.S47073

15. Khalil A, Pajkrt E, Chitty LS. Early prenatal diagnosis of skeletal anomalies. Prenat Diagn 2011;31(1):115-124. DOI:10.1002/pd.2676

16. Krakow D, Lachman RS, Rimoin DL. Guidelines for the prenatal diagnosis of fetal skeletal dysplasias. Genet Med 2009;11(2):127-133. DOI: $10.1097 /$ GIM.0b013e3181971ccb

17. Prashar N, Kalsi M, Gupta S, et al. Pattern of congenital anomalies of musculoskeletal system in newborns: a hospital based study. IOSR J Dent Med Sci 2016;15(5 ver II):56-59. DOI: 10.9790/0853-1505025659

18. Nelson DB, Dashe JS, McIntire DD, et al. Fetal skeletal dysplasias: sonographic indices associated with adverse outcomes. J Ultrasound Med 2014;33:1085-1090 DOI: 10.7863/ultra.33.6.1085

19. Tayebi N, Yazdani K, Naghshin N. The prevalence of congenital malformations and its correlation with consanguineous marriages. Oman Med J 2010;25(1):37-40. DOI: 10.5001/omj.2010.9

20. Gupta RK, Gupta CR, Singh D. Incidence of congenital malformations of the musculoskeletal system in new live borns in Jammu. JK Science 2003;5(4):157-160. ID: sea-171055

21. Oyinbo CA, Dare NW, Amain ED. Prevalence of polydactyly, syndactyly, amniotic band syndrome, cleft lip, cleft palate and talipes equinovarus in Bayelsa state, Nigeria. GMS Med Inform Biom Epidemiol 2009;5(2):14. ISSN 1860-9171

22. Mohammed YA, Shawky MR, Soliman AS, et al. Chromosomal study in newborn infants with congenital anomalies in Assiut University Hospital: Cross-sectional study. Egyptian J Med Hum Genet 2011;12(1):79-90. DOI: 10.1016/j.ejmhg.2011.02.003

23. Bakare T, Sowande OA, Adejuyigbe OO, et al. Epidemiology of external birth defects in neonates in South Western Nigeria. Afr J Paediatr Surg 2009;6(1):28-30. DOI: 10.4103/0189-6725.48572

24. Simpkiss $M$, Lowe A. Congenital abnormalities in the African newborn. Arch Dis Med 1968;22:404-406 DOI: 10.1136/adc.36.188.404

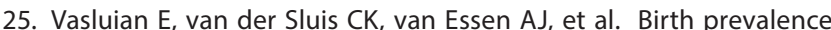
for congenital limb defects in the northern Netherlands: a 30-year population-based study. BMC Musculoskelet Disord 2013;14:323-336 DOI: 10.1186/1471-2474-14-323 
26. Mammen L, Benson CB. Outcome of fetuses with clubfeet diagnosed by prenatal sonography. J Ultrasound Med 2004;23:497-500. DOI: 10.7863/jum.2004.23.4.497

27. Taksande A, Vilhekar K, Chaturvedi P, et al. Congenital malformations at birth in Central India: A rural medical college hospital based data. Indian J Hum Genet. 2010;16(3):159-163. DOI: 10.7863/ jum.2004.23.4.497
28. Shawky RM, Sadik DI. Congenital malformations prevalent among Egyptian children and associated risk factors. Egyptian J Med Hum Genet 2011;12:69-78. DOI: 10.1016/j.ejmhg

29. Mahela S, Talukdar B. Prevalence of congenital abnormalities on routine ultrasound scan of second and third trimester pregnancy. Int J Reprod Contracept Obstet Gynecol 2016;5:182-185. DOI: 10.18203/2320-1770.ijrcog20151621 